\title{
Analisis Perkiraan Tingkat Pelayanan Jalan (Studi Kasus Rencana Tol Dalam Kota Jakarta Ruas Bekasi Raya)
}

\section{(Road Level of Service Analysis (Case Study of Jakarta City Toll Road in Bekasi Raya Segment))}

\author{
Nidea Novitasari ${ }^{1 *}$ dan Tri Sudibyo ${ }^{1}$ \\ ${ }^{1}$ Departemen Teknik Sipil dan Lingkungan, Fakultas Teknologi Pertanian, Institut Pertanian Bogor. \\ Jl. Raya Dramaga, Kampus IPB Dramaga, PO BOX 220, Bogor, Jawa Barat Indonesia \\ *Penulis Korespondensi: nideanovitasari@gmail.com
}

Diterima: 08 Agustus 2019

Disetujui: 19 Desember 2019

\section{ABSTRACT}

In 2017, Jakarta was ranked as $7^{\text {th }}$ most congested city in the world. To overcome the problem of congestion in Jakarta, the government implements the construction of road infrastructure through 6 toll roads inside Jakarta City, but the construction causes pros and contra regarding the effects of induced demand. This research aimed to analyze the service level of Bekasi Raya road on existing and toll roads in Jakarta City and analyzing Bekasi Raya road performance after the operation of the toll road and the offramp impact of toll road. The analysis was conducted based on Indonesian Road Capacity Manual 1997, the Greenshield model, and the Highway Capacity Manual 2000. The result showed that the level of road service in segment 1 was $C$ for Bekasi and D for the Pulogadung direction. In segment 2 the level of service was $E$ for both directions, and in segment 3 the level of service was $C$. The level of the toll road service was $C$ for both directions. The toll roads construction would increase the level of road service to $C$ and reduce vehicle volume of $64.1 \%$ in Bekasi direction and $45.2 \%$ for Pulogadung (Jakarta) direction. The off-ramp impact was the the toll road would not experience significant congestion until 2035.

Keywords: Greenshield model, HCM Model, Indonesian Road Capacity Manual 1997, level of service, toll

\section{PENDAHULUAN}

Jakarta merupakan ibukota Indonesia dan merupakan salah satu kota dengan kepadatan tertinggi ke empat di dunia dengan kondisi mobilitas yang tinggi. Data dari Polda Metro Jaya Tahun 2017 menyatakan bahwa terjadi penambahan unit kendaraan di jalanan sekitar 1 juta unit per tahun. Sementara itu pertumbuhan infrastruktur jalan hanya sebesar $0.01 \%$ per tahun. Meningkatnya kepemilikan kendaraan memicu timbulnya arus lalu lintas yang tidak stabil. Rendahnya tingkat kesadaran masyarakat dalam mematuhi tata tertib lalu lintas menyebabkan konflik lalu lintas dan kemacetan (Widari et al 2015).

Fenomena

pertumbuhan kendaraan menghadirkan polemik baru bagi penduduk Jakarta dan pemerintahannya yaitu tingkat kemacetan yang luar biasa. Kondisi ini diperkuat dengan data yang dirilis oleh Numbeo.com yang menjelaskan bahwa Jakarta adalah kota termacet di dunia pada peringkat 7 pada tahun 2017. Secara garis besar, kemacetan terjadi akibat perbandingan volume per kapasitas yang melebihi 0.75 . Berdasarkan uraian tersebut dapat disimpulkan bahwa upaya mengatasi kemacetan harus secara terpadu dengan penegakan hukum yang tegas (Alhadar 2011). Oleh karena itu, untuk mengatasi masalah kemacetan di Jakarta, Pemerintah melaksanakan pembangunan infrastruktur jalan melalui proyek 6 ruas tol dalam kota DKI Jakarta. Proyek 6 ruas tol dalam kota DKI Jakarta masuk dalam daftar Proyek Strategis Nasional (PSN) yang terlampir dalam Peraturan Presiden Nomor 3 Tahun 2016 maupun 
revisinya dalam Peraturan Presiden Nomor 58 Tahun 2017. Proyek ini masuk ke dalam PSN karena peruntukannya yang strategis dan memiliki urgensi tinggi. Tetapi dalam proses pembangunannya proyek ini sempat akan dibatalkan pengadaanya akibat kontra mengenai pembangunan yang dapat menimbulkan induced demand dan justru akan memperparah kemacetan (LBH Jakarta 2018). Induced demand adalah kondisi dimana ketika terjadi peningkatan suplai maka akan diikuti oleh peningkatan konsumsi, artinya semakin banyak jalan raya dibangun demi pengurangan kemacetan, justru semakin banyak mobil yang akan memakai jalan itu dan membuat jalan itu sesak dan kondisi ini malah memaksa pembangunan lebih banyak jalan raya (Susanto et al 2011). Oleh karena itu, diperlukan perhatian khusus dan analisa lebih lanjut mengenai tingkat pelayanan jalan eksisting pada ruas Bekasi Raya.

Penelitian ini bertujuan untuk: (1) Mengidentifikasi kapasitas jalan, volume kendaraan dan level of service (LOS) Jalan Bekasi Raya pada kondisi eksisting sebelum beroperasinya jalan tol dalam kota Jakarta, (2) Mengidentifikasi kapasitas jalan, volume kendaraan dan level of service (LOS) jalan tol dalam kota Jakarta ruas Bekasi Raya (seksi A Kelapa GadingPulo Gebang), (3) Menganalisis kinerja jalan pasca beroperasinya jalan tol dalam mengurangi kemacetan dan dampak off ramp jalan tol terhadap Jalan Bekasi Raya.

\section{METODOLOGI}

Penelitian diawali dengan survei lapangan untuk mendapatkan jumlah kendaraan, kapasitas jalan dan volume kendaraan yang dilakukan di tiga pos pengamatan, yaitu titik rencana off ramp jalan tol seksi A Kelapa Gading - Pulo Gebang pada jalan Bekasi Raya, titik segmen ruas Jalan Bekasi Raya yang sudah dan belum terpengaruhi pembangunan. Lokasi penelitian dapat dilihat pada Gambar 1. Peralatan yang digunakan dalam penelitian, yaitu formulir pencatatan data, stopwatch, kamera, hand tally counter, meteran dan Microsoft Excel, dan AutoCAD.

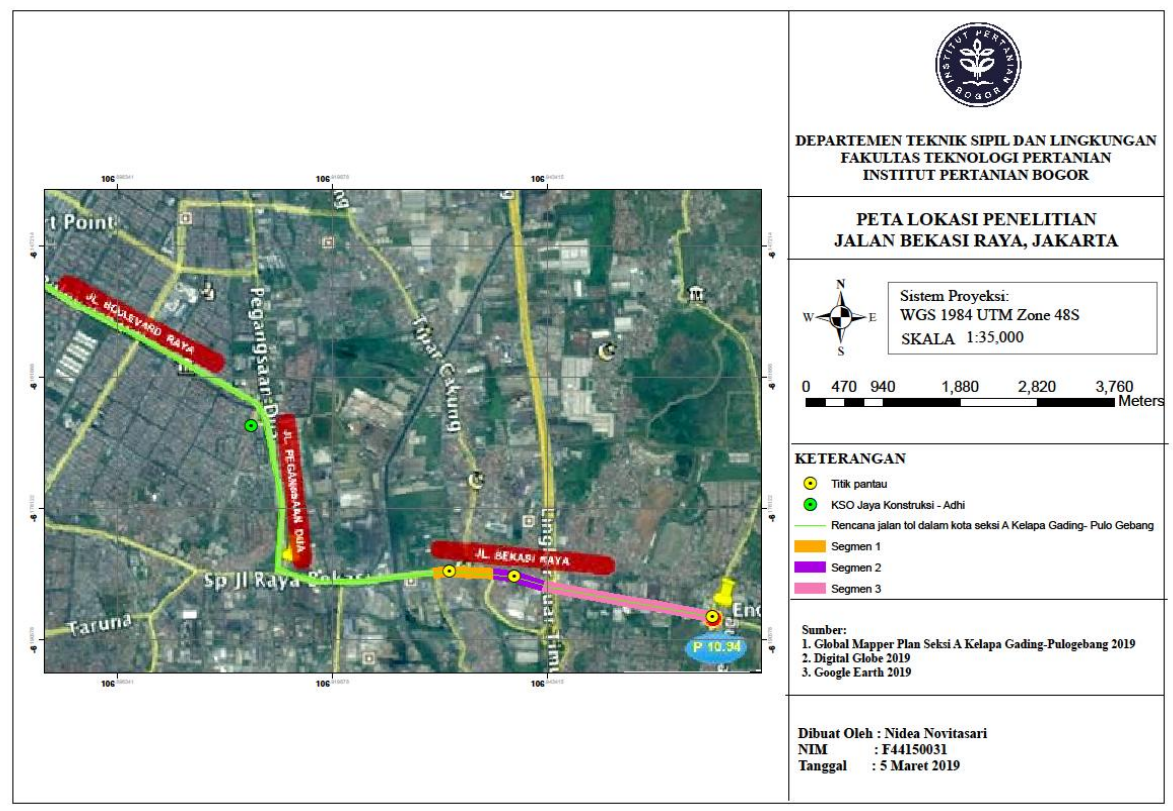

Gambar 1 Peta lokasi penelitian 
Pengumpulan data primer berupa volume lalu lintas dilakukan untuk setiap interval 15 menit setiap jam pengamatan. Pencatatan waktu tempuh kendaraan pada ruas jalan Bekasi Raya dilakukan pada hari Senin dan Sabtu, dari pukul 07.00-09.00 (pagi), 12.0014.00 (siang), dan pukul 16.00-18.00 (sore) WIB. Pengambilan data dilakukan pada Senin dan Sabtu karena hari tersebut dapat mewakili hari kerja dan hari libur sehingga diharapkan data yang didapat valid (Setijadji 2006). Selain itu, dilakukan juga survei hambatan samping selama satu jam dan dihitung pada kedua arah dengan penggal jalan $200 \mathrm{~m}$. Data sekunder berupa detail engineering design (DED) digunakan sebagai penentuan kapasitas berdasarkan geometri jalan tol berupa tipe jalan, medan jalan, lebar bahu jalan dan lebar lajur. Feasibility study digunakan sebagai penentuan volume rencana jalan tol dalam kota seksi A Kelapa Gading Pulo Gebang. Pengolahan data sekunder ini digunakan untuk menganalisis perkiraan nilai tingkat pelayanan atau level of service (LOS) jalan tol dalam kota ruas Bekasi Raya. Analisis yang dilakukan berdasarkan Manual Kapasitas Jalan Indonesia (MKJI) (DepPU 1997), model Greenshield dan Highway Capacity Manual (HCM) 2000 (TRB 2000).

\section{Analisis pada jalan eksisting}

a. Pengolahan berdasarkan metode Manual Kapasitas Jalan Indonesia Jumlah arus lalu lintas yang didapatkan berdasarkan pengambilan data primer dinyatakan dalam kendaraan per hari, smp per jam dan kendaraan per menit. Persamaan (1) digunakan untuk menentukan volume kendaraan. Kapasitas jalan didasarkan pada Manual Kapasitas Jalan Indonesia 1997 (DepPU 1997). Persamaan dasar untuk menentukan kapasitas untuk jalan perkotaan terdapat pada persamaan (2).
Setelah volume dan kapasitas didapatkan dapat dihitung derajat kejenuhan dari jalan tersebut sebagai gambaran apakah suatu ruas jalan mempunyai masalah atau tidak ketika volume ruas jalan makin mendekati kapasitas jalan atau memiliki derajat kejenuhan lebih dari 0.75 (Alhadar 2011). Nilai derajat kejenuhan dihitung dengan persamaan (3) (DepPU 1997).

$\mathrm{Q}=\frac{N}{T}$

C = Cox FCw x FCsp x FCsf $x$ FCcs $(2)$

$\mathrm{DS}=\frac{Q}{C}$

Keterangan:

Q : Volume (kend/jam)

$\mathrm{N}$ : Jumlah kendaraan (kend)

$\mathrm{T}$ : Waktu pengamatan (jam)

C : Kapasitas (smp/jam)

Co : Kapasitas dasar (smp/jam)

FCw: Faktor penyesuaian lebar jalan

FCsp: Faktor penyesuaian pemisah arah

FCsf: Faktor penyesuaian untuk hambatan samping dan bahu jalan atau kereb

FCcs: Faktor penyesuaian ukuran kota

DS : Derajat kejenuhan

Q : Volume lalu lintas maksimum (smp/jam)

C : Kapasitas jalan lalu lintas pada segmen yang ditinjau (smp/jam)

Berdasarkan kondisi geometrik jalan eksisting Bekasi Raya berupa lebar jalur, lebar bahu dan survei hambatan samping maka kecepatan arus bebas dapat dihitung berdasarkan persamaan (4). Kecepatan arus bebas dan derajat kejenuhan yang dihasilkan maka akan didapatkan kecepatan tempuh rata-rata melalui Gambar 2. Berdasarkan kecepatan yang didapat dan kondisi hambatan samping maka dapat ditentukan tingkat pelayanan jalan atau level of service (LOS) berdasarkan pada 
Peraturan Mentri Nomor 96 mengenai tingkat pelayanan jalan perkotaan (KemenHub 2015).

$\mathrm{FV}=\left(\mathrm{FV}_{0}+\mathrm{FV}_{\mathrm{w}}\right) \times \mathrm{FFV}_{\mathrm{SF}} \times \mathrm{FFV}_{\mathrm{CS}}$

Keterangan:

FV : Kecepatan arus bebas kendaraan ringan pada kondisi lapangan $(\mathrm{km} / \mathrm{jam})$

$\mathrm{FV}_{0}$ :Kecepatan arus bebas dasar kendaraan ringan pada jalan yang diamati

$\mathrm{FV}_{\mathrm{w}}$ :Penyesuaian kecepatan untuk lebar jalur ( $\mathrm{km} / \mathrm{jam})$

$\mathrm{FFV}_{\mathrm{SF}}$ :Faktor penyesuaian untuk hambatan samping dan lebar bahu atau jarak kerb penghalang

$\mathrm{FFV}_{\mathrm{CS}}$ :Faktor penyesuaian kecepatan untuk ukuran kota

b. Pengolahan berdasarkan model Greenshield
Analisis menggunakan permodelan matematis Greenshield menggunakan data primer berupa volume lalu lintas dan kecepatan kendaraan (Julianto 2010). Menurut Apriliyanto (2018), terdapat empat langkah utama dalam proses membangun model korelasi $\mathrm{Q}-\mathrm{V}-\mathrm{K}$, yaitu survei dan pengambilan data, proses validasi data, pengembangan model korelasi dan analisis model korelasi. Analisis model korelasi ini ialah untuk mendapatkan parameterparameter pengukuran kinerja jalan seperti kapasitas maksimum (Qm), kecepatan pada saat arus maksimum (Vm) dan kerapatan pada saat arus maksimum $(\mathrm{Km})$. Analisis ini dipilih berdasarkan nilai $\mathrm{R}^{2}$ untuk mendapatkan tingkat kepercayaan tertinggi korelasi data (Pratomo dan Astuti 2015). Nilai $R^{2}$ yang dapat digunakan yaitu memiliki nilai lebih besar dari 0.8 yang diartikan korelasi sangat kuat.

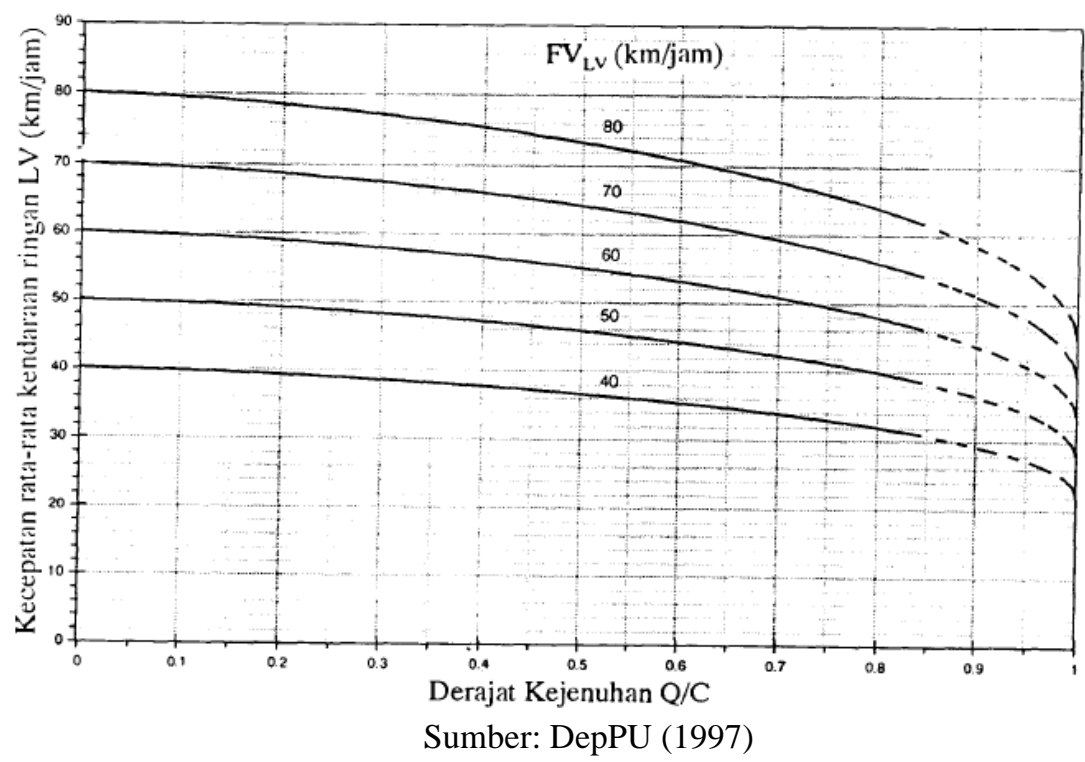

Gambar 2 Hubungan antara derajat kejenuhan dengan kecepatan arus bebas

Analisis pada jalan bebas hambatan

a. Pengolahan berdasarkan metode Manual Kapasitas Jalan Indonesia

Perkiraan volume lalu lintas pada jalan bebas hambatan dapat dilakukkan menggunakan data LHRT (lalu lintas harian rata-rata tahunan) apabila data arus jam perencanaan dalam kendaraan/jam tidak tersedia. Perhitungan volume lalu lintas rencana terlihat pada persamaan (5). Kapasitas jalan bebas hambatan ditetapkan berdasarkan tipe jalan, lebar lajur, tipe alinyemen, pemisah arah SP, dan arus 
lalu lintas per arah (DepPU 1997) yang terlihat pada persamaan (6). Kecepatan arus bebas untuk jalan bebas hambatan didasarkan pada MKJI 1997. Persamaan (7) digunakan untuk menentukan kecepatan arus bebas (DepPU 1997).

$$
\begin{aligned}
& \mathrm{QDH}=\mathrm{LHRT} \times \mathrm{K} \times \mathrm{P} \\
& \mathrm{C}=\mathrm{Co} \times \mathrm{FCw} \times \mathrm{FC} \\
& \mathrm{FV}=\mathrm{FV}_{0}+\mathrm{FV}_{\mathrm{w}}
\end{aligned}
$$

Keterangan:

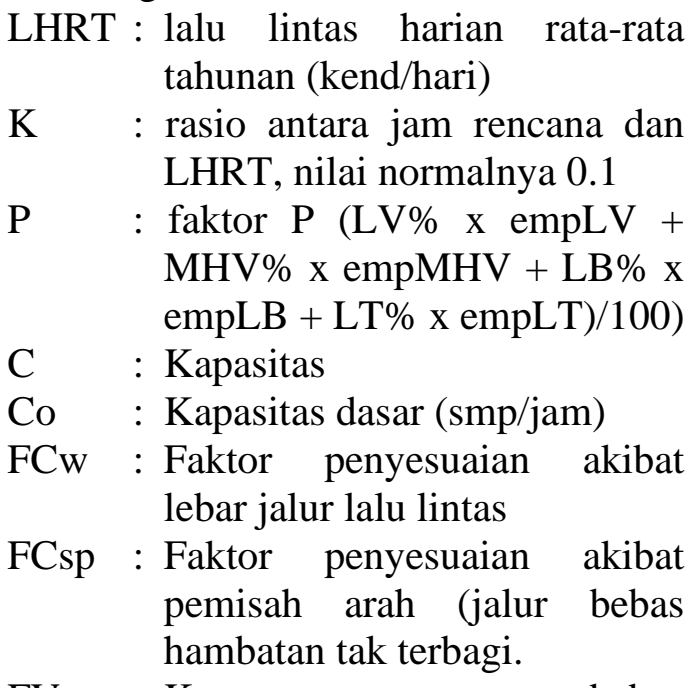

FV : Kecepatan arus bebas kendaraan ringan pada kondisi lapangan $(\mathrm{km} / \mathrm{jam})$

$\mathrm{FV}_{0}$ : Kecepatan arus bebas dasar kendaraan ringan untuk kondisi jalan dan tipe alinyemen yang dipelajari.

$\mathrm{FV}_{\mathrm{w}}$ : Penyesuaian kecepatan untuk lebar jalan $(\mathrm{km} / \mathrm{jam})$

b. Pengolahan berdasarkan Highway Capacity Manual 2000

Perkiraan volume lalu lintas pada jalan bebas hambatan dipengaruhi oleh proporsi kendaraan yang bergerak pada arah yang memiliki arus puncak pada jam-jam sibuk dilambangkan dengan D untuk jalan dua lajur. Sedangkan proporsi dari LHRT dilambangkan dengan faktor K. Menurut Khisty dan Lall (2006), besaran nilai D untuk perkotaan yaitu 0.52 . Faktor-K yang digunakan untuk jalan perkotaan adalah 0.093 (FDT 1995). Volume jam rencana dihitung berdasarkan persamaan (8).

Berdasarkan volume jam rencana yang didapat maka dapat dihitung arus lalu lintas selama 15 menit seperti pada persamaan (9). Faktor penyesuaian kendaraan berat (fhv) dapat dilihat pada persamaan (10). Nilai RVs dianggap 0 apabila perbandingan truk memiliki komposisi lima persen lebih besar dibandingkan RVs (Nathaniel 2010). Kecepatan arus bebas terlihat pada persamaan (10) (TRB 2000).

Berdasarkan kecepatan arus bebas yang didapat, dapat dihitung nilai kecepatan minimum dengan formula: jika $90 \leq \mathrm{FFS} \leq 120$ dan Vp diantara $(3.100-15 \mathrm{FFS})<\mathrm{Vp} \leq(1.800+5 \mathrm{FFS})$ maka menggunakan persamaan (12). Jika $90 \leq$ FFS $\leq 120$ dan $\mathrm{Vp} \leq$ (3.10015FFS) maka menggunakan persamaan kecepatan minimum sama dengan kecepatan arus bebas.

Arus lalu lintas dan kecepatan minimum yang dihasilkan maka akan didapatkan kepadatan seperti pada persamaan (13). Nilai arus lalu lintas, kecepatan arus bebas dan kecepatan minimum yang dihasilkan maka akan didapatkan tingkat pelayanan jalan sesuai metode Highway Capacity Manual pada Gambar 3.

$\mathrm{DDHV}=\mathrm{AADT} \times \mathrm{K} \times \mathrm{D}$

$\mathrm{Vp}=\frac{D D H V}{P H F \times N \times f H V \times f p}$

$\mathrm{f}_{\mathrm{HV}}=\frac{1}{1+P t(E t-1)+\operatorname{Pr}(E r-1)}$

$F F S=B F F S-f_{L W}-f_{L C}-f_{N}-f_{D}$

$\mathrm{S}=\mathrm{FFS}-\left[\frac{1}{28} x(23 F F S-\right.$

$$
\mathrm{D}=\frac{V p}{S}
$$

Keterangan:

DDHV : volume jam rencana (kendaraan/jam) 

AADT : lalu lintas harian rata-rata tahunan (kendaraan/hari)
$\mathrm{K}$ : proporsi AADT yang terjadi pada jam sibuk
D : proporsi dari lalu lintas jam sibuk terarah.
$\mathrm{Vp}$ : flow rate mobil penumpang selama $15 \quad$ menit (smp/lajur/jam)

DDHV : directional design-hour volume (kendaraan/jam)

PHF : peak hour factor (berdasarkan data feasibility study $=0.87$ )

$\mathrm{N}$ : jumlah lajur

Fhv : faktor penyesuaian kendaraan berat

fp : faktor populasi pengemudi (fp $=1$, asumsi pengemudi komuter)

Et : padanan mobil penumpang untuk bus dan truk

Er : padanan mobil penumpang untuk recreational vehicle

$\mathrm{Pt} \quad$ : proporsi dari bus dan truk

Pr : proporsi dari recreational vehicle

FFS : kecepatan arus bebas (km/jam)

BFFS : kecepatan arus bebas dasar (perkotaan $110 \mathrm{~km} / \mathrm{jam}$ )

$\mathrm{f}_{\mathrm{LW}}$ : penyesuaian terhadap lebar lajur (km/jam)

$\mathrm{f}_{\mathrm{LC}}$ : penyesuaian terhadap kebebasan samping ( $\mathrm{km} / \mathrm{jam})$

$\mathrm{f}_{\mathrm{N}} \quad$ : penyesuaian tehadap jumlah lajur $(\mathrm{km} / \mathrm{jam})$

$\mathrm{f}_{\mathrm{D}}$ : penyesuaian terhadap kepadatan persimpangan $(\mathrm{km} / \mathrm{jam})$

$\mathrm{S} \quad$ : kecepatan minimum

D : kepadatan (smp/km/lajur)
$\mathrm{Vp} \quad$ : flow rate (smp/jam/lajur)

$\mathrm{S} \quad$ : kecepatan minimum $(\mathrm{km} / \mathrm{jam})$

\section{Analisis bagian jalinan}

Kapasitas total bagian jalinan terlihat pada persamaan (14). Derajat kejenuhan bagian jalinan berdasarkan MKJI 1997 mempertimbangkan arus total (smp/jam) yang didasarkan pada faktor smp (satuan mobil penumpang). Adapun rumus mengenai kapasitas jalinan tunggal seperti pada persamaan (15) (DepPU 1997). Kemudian dihitung kecepatan arus bebas pada persamaan (16) berdasarkan kecepatan tempuh pada persamaan (17) (DepPU 1997).

$$
\begin{aligned}
& \mathrm{C}= 135 \times \mathrm{W}_{\mathrm{W}}^{1.3} \times\left(1+\mathrm{W}_{\mathrm{E}} / \mathrm{W}_{\mathrm{W}}\right)^{1.5} \times(1- \\
&\left.\mathrm{p}_{\mathrm{w}} / 3\right)^{0.5} \times\left(1+\mathrm{W}_{\mathrm{W}} / \mathrm{L}_{\mathrm{W}}\right)^{-1.8} \times \mathrm{F}_{\mathrm{CS}} \times \mathrm{F}_{\mathrm{RSU}}
\end{aligned}
$$

$\mathrm{DS}=\mathrm{Q}_{\mathrm{smp}} / \mathrm{C}$

$\mathrm{Vo}=43 \times\left(1-\mathrm{p}_{\mathrm{w}} / 3\right)$

$\mathrm{V}=\mathrm{Vo} \times 0.5 \times\left(1+(1-\mathrm{DS})^{0.5}\right)$

Keterangan:

$\mathrm{W}_{\mathrm{E}}$ : lebar masuk rata-rata $(\mathrm{m})$

$\mathrm{W}_{\mathrm{W}}$ : lebar jalinan $(\mathrm{m})$

$\mathrm{LW}_{\mathrm{W}}$ : panjang jalinan (m)

$\mathrm{F}_{\mathrm{CS}}$ : faktor penyesuaian ukuran kota

FRSU : faktor penyesuaian rasio kendaraan tak bermotor

$\mathrm{p}_{\mathrm{w}} \quad$ : rasio jalinan

$\mathrm{Q}_{\text {smp }} \quad$ : arus total (smp/jam)

$\mathrm{F}_{\mathrm{smp}} \quad$ : faktor smp

C : kapasitas (smp/jam)

Vo : kecepatan arus bebas $(\mathrm{km} / \mathrm{jam})$

$\mathrm{p}_{\mathrm{w}} \quad$ : rasio jalinan

Vo : kecepatan arus bebas $(\mathrm{km} / \mathrm{jam})$

DS : derajat kejenuhan Kecepatan arus bebas. 


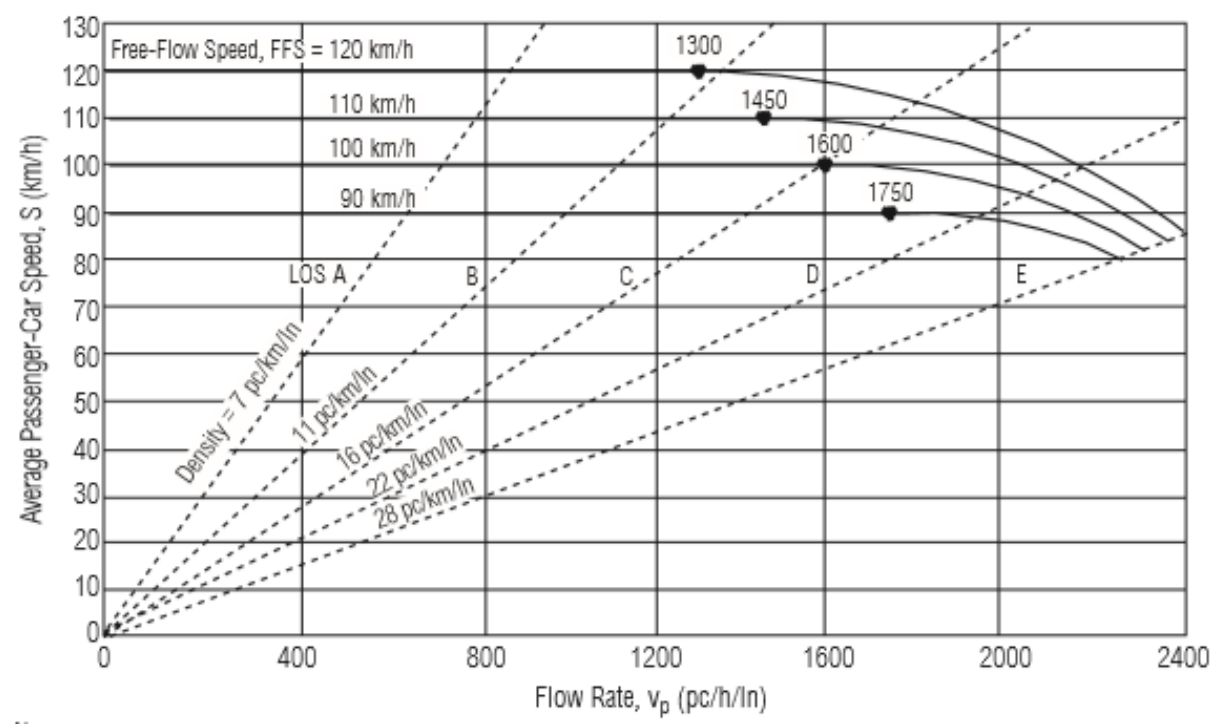

Sumber: TRB 2000

Gambar 3 Hubungan antara laju kecepatan dan level of service pada basic freeway segments

\section{HASIL DAN PEMBAHASAN}

\section{Evaluasi Kondisi Jalan Bekasi Raya Pada Kondisi Eksisting}

Jalan Bekasi Raya merupakan jalan nasional yang menghubungkan Kota Jakarta dengan Kota Bekasi. Berdasarkan Keputusan Menteri Pekerjaan Umum No. 631/KPTS/M/2009 pada tanggal 31 Desember 2009 bahwa Jalan Bekasi Raya memiliki status jalan nasional bukan jalan tol dengan panjang ruas
7.038 km. Jalan Bekasi Raya terletak pada Kecamatan Pulogadung dan Kecamatan Cakung, Kotamadya Jakarta Timur dan termasuk kedalam jalan arteri primer yang menghubungkan Kota Jakarta dan Kota Bekasi. Jalan Bekasi Raya merupakan salah satu ruas yang masuk dalam rencana pembangunan tol dalam Kota Jakarta seksi A Kelapa Gading-Pulo Gebang. Struktur jaringan jalan Bekasi Raya terlihat pada Tabel 1. Kondisi geometri jalan berdasarkan hasil survei lapangan terlihat pada Tabel 2.

Tabel 1 Struktur jaringan jalan Bekasi Raya

\begin{tabular}{lllllllc}
\hline Titik & \multicolumn{1}{c}{ Keterangan } & $\begin{array}{c}\text { Nama ruas } \\
\text { jalan }\end{array}$ & Status & $\begin{array}{c}\text { Kelas } \\
\text { fungsi }\end{array}$ & $\begin{array}{c}\text { Kelas } \\
\text { jalan }\end{array}$ & $\begin{array}{c}\text { Tipe } \\
\text { jalan }\end{array}$ & $\begin{array}{c}\text { Jumlah } \\
\text { penduduk }\end{array}$ \\
\hline 1 & $\begin{array}{l}\text { Titik Belum } \\
\text { Terpengaruhi } \\
\text { Proyek }\end{array}$ & Bekasi Raya & Nasional & $\begin{array}{c}\text { Arteri } \\
\text { primer }\end{array}$ & khusus & $5 / 2 \mathrm{D}$ & $10.37 \mathrm{jt}$ \\
2 & Bekasi Raya & Nasional & $\begin{array}{l}\text { Arteri } \\
\text { pitik } \\
\text { Terpengaruhi }\end{array}$ & khusus & $2 / 2 \mathrm{D}$ & $10.37 \mathrm{jt}$ \\
& $\begin{array}{l}\text { Proyek } \\
\text { Jalan rencana off } \\
\text { ramp }\end{array}$ & Bekasi Raya & Nasional & $\begin{array}{l}\text { Arteri } \\
\text { primer }\end{array}$ & khusus & $6 / 2 \mathrm{D}$ & $10.37 \mathrm{jt}$ \\
\hline
\end{tabular}


JSIL | Novitasari \& Sudibyo. : Analisis Perkiraan Tingkat Pelayanan Jalan

Tabel 2 Kodisi geometri jalan Bekasi Raya saat ini

\begin{tabular}{|c|c|c|c|c|c|c|}
\hline Titik & Arah & $\begin{array}{l}\text { Lebar jalur } \\
\quad(\mathrm{m})\end{array}$ & $\begin{array}{l}\text { Bahu/ } \\
\text { kereb }\end{array}$ & $\begin{array}{l}\text { Lebar bahu/ } \\
\text { kereb }(\mathrm{m})\end{array}$ & Median & Tipe jalan \\
\hline \multirow[t]{2}{*}{1} & Bekasi & 13.7 & Bahu & 1.5 & Ada & $5 / 2 \mathrm{D}$ \\
\hline & Pulogadung & 10.1 & Kereb & 0.6 & Ada & \\
\hline \multirow[t]{2}{*}{2} & Bekasi & 3.5 & Bahu & 1.96 & Ada & $2 / 2 \mathrm{D}$ \\
\hline & Pulogadung & 3.9 & Kereb & 0.6 & Ada & \\
\hline \multirow[t]{2}{*}{3} & Bekasi & 13.6 & Kereb & 0.9 & Ada & $6 / 2 \mathrm{D}$ \\
\hline & Pulogadung & 13.9 & Kereb & 1.5 & Ada & \\
\hline
\end{tabular}

a) Evaluasi menggunakan metode Manual Kapasitas Jalan Indonesia 1997

Kondisi geometri jalan yaitu lebar jalur, lebar bahu atau kereb dan hambatan samping akan mempengaruhi kapasitas dan kecepatan arus bebas. hasil survei, hambatan samping pada ketiga segmen diklasifikasikan rendah. Hasil perhitungan untuk mengetahui kinerja ruas jalan berdasarkan perhitungan yang terdapat pada Manual Kapasitas Jalan Indonesia 1997 terlihat pada Tabel 3. Tingkat pelayanan jalan pada segmen 1 arah Bekasi adalah $\mathrm{C}$ yang diartikan arus stabil dengan volume lalu lintas yang lebih tinggi dan memiliki kecepatan sekurang-kurangnya $60 \quad \mathrm{~km} / \mathrm{jam}$ (KemenHub 2015). Sedangkan tingkat pelayanan jalan pada segmen 1 arah Pulogadung adalah D yang diartikan arus mendekati tidak stabil dengan volume lalu lintas tinggi dan memiliki kecepatan sekurang-kurangnya $\quad 50 \quad \mathrm{~km} / \mathrm{jam}$ (KemenHub 2015). Pada kondisi tingkat pelayanan $\mathrm{D}$ pengemudi memiliki kebebasan yang sangat terbatas. Tingkat pelayanan jalan pada segmen 2 arah Bekasi dan Pulogadung adalah E yang diartikan arus mendekati tidak stabil dengan volume lalu lintas mendekati kapasitas jalan dan memiliki kecepatan sekurang-kurangnya $\quad 10 \quad \mathrm{~km} / \mathrm{jam}$ (KemenHub 2015). Pada kondisi tingkat pelayanan $\mathrm{E}$ pengemudi mulai merasakan kemacetan-kemacetan durasi pendek. Tingkat pelayanan jalan pada segmen 3 atau jalan off ramp rencana adalah $\mathrm{C}$ sehingga jalan ini dinilai cukup baik untuk dijadikan jalan yang berhubungan dengan off ramp jalan tol.

b) Evaluasi menggunakan model Greenshield

Pengembangan model korelasi model Greenshield berdasarkan datadata primer, yaitu data volume lalu lintas dan kecepatan kendaraan yang sudah didapatkan. Hal yang cukup penting dan perlu diperhatikan adalah model korelasi yang akan dibangun akan valid jika dan hanya jika survei dilakukan pada ruas jalan yang sama dan periode waktu yang sama juga (Apriliyanto 2018). Korelasi dikembangkan berdasarkan hubungan Q-V-K yaitu parameter kapasitas maksimum $\left(\mathrm{Q}_{\mathrm{m}}\right)$, kecepatan pada saat arus maksimum $\left(\mathrm{V}_{\mathrm{m}}\right)$ dan kerapatan pada saat arus maksimum $\left(\mathrm{K}_{\mathrm{m}}\right)$. Data dinilai valid jika hubungan korelasi pada ketiga fungsi ini memiliki nilai lebih besar dari 0.8 yang menandakan hubungan antar variabel sangat kuat (Pratomo dan Astuti 2015). Hasil kinerja ruas jalan terlihat pada Tabel 4. 
Tabel 3 Kinerja ruas jalan berdasarkan metode MKJI 1997

\begin{tabular}{llcccccc}
\hline Segmen & Arah & $\begin{array}{c}\text { Arus } \\
\text { lalu } \\
\text { lintas } \\
(\mathrm{smp} / \\
\text { jam) }\end{array}$ & $\begin{array}{c}\text { Kapasitas } \\
(\mathrm{smp} / \mathrm{jam})\end{array}$ & $\begin{array}{c}\text { Derajat } \\
\text { kejenuhan }\end{array}$ & $\begin{array}{c}\text { Kecepatan } \\
\text { arus bebas } \\
(\mathrm{km} / \mathrm{jam})\end{array}$ & $\begin{array}{c}\text { Kecepatan } \\
(\mathrm{km} / \mathrm{jam})\end{array}$ & LOS \\
\hline 1 & Bekasi & 1339 & 5560 & 0.24 & 64 & 62 & $\mathrm{C}$ \\
& Pulogadung & 1742 & 3558 & 0.49 & 62 & 58 & $\mathrm{D}$ \\
2 & Bekasi & 1225 & 1569 & 0.77 & 44 & 38 & $\mathrm{E}$ \\
& Pulogadung & 1777 & 1872 & 0.95 & 50 & 35 & $\mathrm{E}$ \\
& Bekasi & 1370 & 5382 & 0.25 & 66 & 66 & $\mathrm{C}$ \\
& Pulogadung & 1432 & 5471 & 0.26 & 66 & 66 & $\mathrm{C}$ \\
\hline
\end{tabular}

Tabel 4 Kinerja ruas jalan berdasarkan model Greenshield

\begin{tabular}{llccccc}
\hline Segmen & \multicolumn{1}{c}{ Arah } & $\begin{array}{c}\text { Arus lalu lintas } \\
(\mathrm{smp} / \mathrm{jam})\end{array}$ & $\begin{array}{c}\text { Kapasitas } \\
(\mathrm{smp} / \mathrm{jam})\end{array}$ & $\begin{array}{c}\text { Derajat } \\
\text { kejenuhan }\end{array}$ & $\begin{array}{c}\text { Kecepatan } \\
(\mathrm{km} / \mathrm{jam})\end{array}$ & LOS \\
\hline 1 & Bekasi & 1339 & 1325 & 1.01 & 11.84 & $\mathrm{~F}$ \\
2 & Bekasi & 1225 & 1225 & 0.90 & 7.45 & $\mathrm{~F}$ \\
& Pulogadung & 1777 & 1359 & 0.95 & 9.32 & $\mathrm{~F}$ \\
3 & Bekasi & 1370 & 1443 & 0.95 & 19.95 & $\mathrm{E}$ \\
& Pulogadung & 1432 & 1532 & 0.93 & 13.20 & $\mathrm{E}$ \\
\hline
\end{tabular}

Berdasarkan Tabel 4 segmen 1, untuk arah Pulogadung grafik hubungan antara kerapatan dan arus lalu lintas maksimum tidak berbentuk parabolik sehingga tidak dapat ditentukan arus lalu lintas maksimum (kapasitas jalan) sehingga untuk korelasi selanjutnya tidak dapat berhubungan dikarekanakan data tidak valid. Tingkat pelayanan jalan untuk arah Bekasi maupun Pulogadung pada segmen 1 dan segmen 2 adalah $\mathrm{F}$ dengan derajat kejenuhan lebih dari 0.9 yang diartikan sangat buruk karena hampir mendekati kapasitas jalan yang ada. Tingkat pelayanan jalan untuk arah Bekasi maupun Pulogadung adalah E dengan derajat kejenuhan lebih dari 0.9 yang diartikan sangat buruk karena hampir mendekati kapasitas jalan yang ada. Kondisi jalan pada tingkat pelayanan $\mathrm{E}$ yang diartikan arus mendekati tidak stabil dengan volume lalu lintas mendekati kapasitas jalan dan memiliki kecepatan sekurang-kurangnya 10 km/jam (KemenHub 2015). Kondisi jalan pada tingkat pelayanan $\mathrm{F}$ yaitu terjadi antrian kendaraan yang panjang dengan kecepatan mapun volume dapat turun sampai 0. Kapasitas jalan pada metode Greenshield bersifat fleksibel mengikuti arus lalu lintas yang melewati ruas jalan tersebut. Berdasarkan hasil analisis menggunakan kedua metode ini, hasil yang dipilih adalah menggunakan metode MKJI karena beberapa data tidak memiliki nilai korelasi variabel yang sangat kuat atau nilai $\mathrm{R}^{2}$ kurang dari 0.8 .

Berdasarkan evaluasi ketiga ruas jalan, pada segmen 1 dianggap sebagai kondisi asli jalan tersebut sebelum dilakukan penyempitan lajur. Tingkat pelayanan jalan pada segmen 1 di tahun 2019 arah Bekasi adalah C sedangkan untuk arah Pulogadung adalah D. Segmen 2 terjadi penyempitan lajur 
sehingga nilai tingkat pelayanan jalan untuk kedua arah turun menjadi $\mathrm{E}$. Berdasarkan hasil evaluasi pada segmen 1 dan segmen 2, jalan Bekasi Raya pada kondisi eksisting ini tidak memenuhi standar tingkat pelayanan jalan yang tertulis pada PRI Nomor 34 tahun 2006 dengan tingkat pelayanan jalan arteri primer adalah $\mathrm{C}$, sehingga diperlukan rekomendasi untuk memperbaiki kinerja jalan tersebut agar dapat menampung arus lalu lintas yang ada. Segmen 3 memiliki tingkat pelayanan jalan untuk kedua arah adalah $\mathrm{C}$, sehingga jalan ini sesuai dengan standar yang ada. Untuk mengurangi arus lalu lintas pada jalan eksisting, pemerintah melakukan pembangunan tol dalam Kota Jakarta Seksi A Kelapa Gading-Pulo Gebang.

\section{Evaluasi Kinerja Jalan Pada Perencanaan Jalan Tol}

Jalan tol dalam kota Jakarta Seksi A Kelapa Gading-Pulo Gebang termasuk kedalam rencana 6 Ruas Jalan Tol Dalam Kota Jakarta. 6 Ruas Jalan Tol Dalam
Kota Jakarta dicantumkan dalam RTRW DKI Jakarta tahun 2030 sesuai PERDA DKI No.1 Tahun 2012. 6 Ruas Jalan Tol dalam Kota Jakarta masuk dalam Proyek Strategis Nasional berdasarkan PerPres No. 3 Tahun 2016 dan PerPres No. 58 Tahun 2017 mengenai Percepatan Pelaksanaan Proyek Strategis Nasional. Tol dalam kota Jakarta Seksi A Kelapa Gading-Pulo Gebang termasuk dalam pembangunan Trase Tahap 1 Pembagian seksi jalan pada Tahap 1 terlihat pada Gambar 4.

Jalan tol dalam Kota Jakarta Seksi A Kelapa Gading-Pulo Gebang memilik enam lajur dan pada tiap jalur terdiri dari tiga lajur dengan status jalan nasional yang diklasifikasikan kelas jalan I dengan fungsi jalan arteri. Jalan tol dalam kota Jakarta Seksi A Kelapa Gading-Pulo Gebang memiliki tipe jalan $6 / 2 \mathrm{D}$ atau enam lajur dua arah terbagi dengan perencanaan geometri jalan pada segmen maupun ramp seperti pada Tabel 5 .

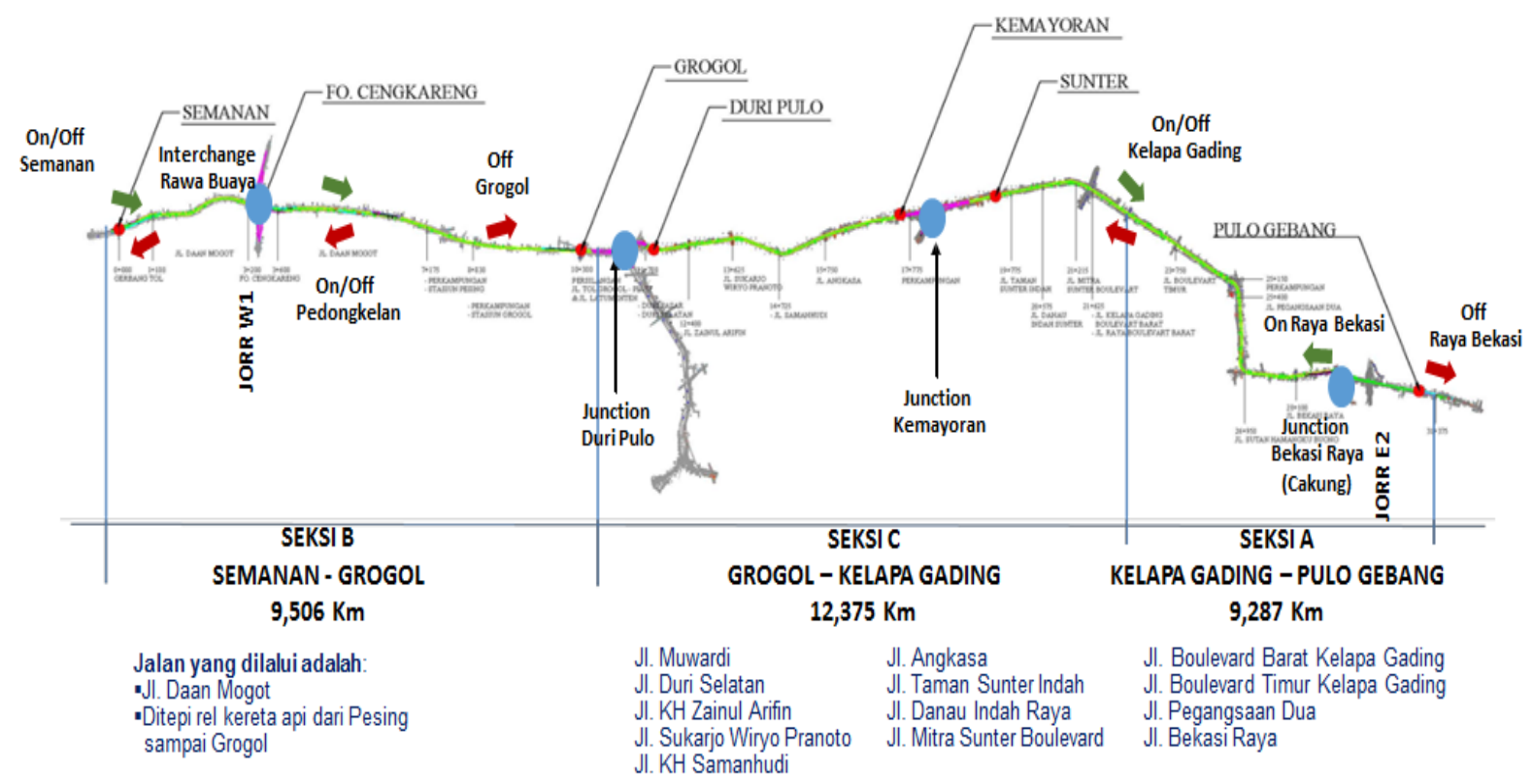

Gambar 4 Trase Tahap 1 (Semanan - Grogol - Pulo Gebang) 
Tabel 5 Perencanaan geometri jalan tol dalam kota Jakarta seksi A Kelapa Gading-Pulo Gebang

\begin{tabular}{lccc}
\hline Parameter geometri & \multicolumn{3}{c}{ Ukuran desain } \\
ramp 1/1 & ramp 2/1 \\
\hline Lebar lajur (m) & 3.5 & 4 & 3.5 \\
Lebar bahu luar (m) & 2.0 & 3 & 0.5 \\
Lebar bahu dalam (m) & 0.5 & 1 & 0.5 \\
Lebar median (termasuk bahu dalam) (m) & 1.8 & tidak ada & tidak ada \\
Superelevasi maksium (\%) & 6 & 6 & 6 \\
Jarak pandang henti minimum (m) & 75 & 40 & 40 \\
Kelandaian maksimum (\%) & 5 & 7 & 7 \\
Kecepatan rencana (km/jam) & 60 & 40 & 40 \\
\hline
\end{tabular}

Penilaian ruas jalan tol menggunakan dua metode yaitu perumusan dari Manual Kapasitas Jalan Indonesia 1997 dan Highway Capacity Manual (HCM) 2000. Nilai tingkat pelayanan jalan kedua metode ini dibandingkan. Kinerja yang ditinjau hanya sampai segmen jalan. Hal ini dikarenakan pada MKJI 1997 maupun HCM 2000 (TRB 2000), rumus untuk kapasitas jalur penghubung ( $\mathrm{ramp}$ ) yang dianalisis dapat diperhitungkan jika suatu jalur penghubung pada segmen yang sama. Arah laju kendaraan yang dianalisis yaitu arah Pulo Gebang (Bekasi) dan Kelapa Gading (Jakarta). Data kondisi lalu lintas yang digunakan adalah volume lalu lintas harian rata-rata (LHR) pada feasibility study 6 Ruas Jalan Tol Dalam Kota Jakarta untuk tahun 2021 yang kemudian diproyeksikan ke tahun 2024 ketika beroperasinya jalan tol.

a) Evaluasi menggunakan metode MKJI 1997

Hasil perhitungan untuk mengetahui perkiraan kinerja ruas jalan berdasarkan perhitungan yang terdapat pada Manual Kapasitas Jalan Indonesia 1997 terlihat pada Tabel 6. Arus lalu lintas maksimum untuk arah Pulo Gebang sebesar 3927 smp/jam dan untuk arah Kelapa Gading sebesar 3319 smp/jam. Kapasitas yang dapat ditampung oleh jalan arah Pulo Gebang dan Kelapa Gading yang terdiri dari tiga lajur yaitu $6900 \mathrm{smp} / \mathrm{jam}$. Tingkat pelayanan jalan tol pada kedua arah ini adalah $\mathrm{C}$ dimana arus masih stabil dengan volume pelayanan tidak melebihi 75\% dari kapasitas jalan (BSN 2008).

b) Evaluasi menggunakan metode Highway Capacity Manual 2000

Hasil perhitungan untuk mengetahui perkiraan kinerja ruas jalan berdasarkan perhitungan yang terdapat pada HCM 2000 (TRB 2000) terlihat pada Tabel 7. Berbeda dengan metode MKJI 1997, metode HCM 2000 menganalisis tingkat pelayanan per lajur jalan. Tingkat pelayanan ditetapkan berdasarkan kecepatan arus bebas, arus lalu lintas per lajur dalam smp/jam, densitas, maksimum V/C dan kapasitas jalan. Kapasitas yang ditampung berdasarkan metode MKJI didasarkan pada faktor penyesuaian akibat lebar jalur lalu lintas dan akibat pemisah arah. Kapasitas jalan pada metode HCM 2000 bersifat fleksibel karena mengikuti nilai maksimum rasio $\mathrm{V} / \mathrm{C}$.

Tingkat pelayanan per lajur untuk arah Pulo Gebang pada tahun 2024 adalah C karena memiliki densitas 
kurang dari $16 \mathrm{smp} / \mathrm{km} / \mathrm{lajur}$. Tingkat pelayanan per lajur untuk arah Kelapa Gading pada tahun 2024 adalah B karena memiliki densitas kurang dari 11 smp/km/lajur. Kapasitas untuk arah Kelapa Gading lebih besar dibandingkan arah Pulo Gebang karena memiliki tingkat pelayanan jalan yang berbeda, sehingga nilai maksimum rasio $\mathrm{V} / \mathrm{C}$ yang ditetapkan berbeda.

\section{Analisis Perkiraan Kinerja Jalan Pasca Jalan Tol Beroperasi}

Jalan Bekasi Raya setelah beroperasinya jalan tol memiliki median $5 \mathrm{~m}$ pada setiap segmen yaitu $4 \mathrm{~m}$ digunakan sebagai kolom jalan tol, dan $0.5 \mathrm{~m}$ pada masing-masing arah adalah marka jalan atau bahu dalam. Tipe jalan untuk segmen 1 dan segmen 2 menjadi $6 / 2 \mathrm{D}$, dengan lebar tiap lajur $3.25 \mathrm{~m}$. Untuk segmen 3 menjadi 8/2 D. Pada arah Bekasi memiliki 5 lajur dan arah Pulo Gadung menjadi 3 lajur, sehingga lebar masing-masing jalur adalah $9.75 \mathrm{~m}$ dan menggunakan kereb sebesar $2 \mathrm{~m}$. Volume lalu lintas yang terjadi di Jalan Bekasi Raya pada tahun 2019 diproyeksikan ke tahun 2024 menggunakan metode bunga majemuk kemudian dikurangi dengan volume yang ada pada jalan tol maka akan didapatkan persentasi teralihkan. Berdasarkan Tabel 8, perkiraan volume kendaraan maksimum yang dapat dikurangi untuk arah Bekasi sampai dengan $64.1 \%$, sedangkan untuk arah Pulogadung mencapai $45.2 \%$.

Tabel 6 Perkiraan kinerja ruas jalan tol menggunakan MKJI 1997

\begin{tabular}{lcccccc}
\hline Arah & $\begin{array}{c}\text { Arus lalu } \\
\text { lintas } \\
(\mathrm{smp} / \mathrm{jam})\end{array}$ & $\begin{array}{c}\text { Kapasitas } \\
(\text { smp/jam })\end{array}$ & $\begin{array}{c}\text { Derajat } \\
\text { kejenuhan }\end{array}$ & $\begin{array}{c}\text { Kecepatan } \\
\text { arus bebas } \\
(\mathrm{km} / \mathrm{jam})\end{array}$ & $\begin{array}{c}\text { Kecepatan } \\
(\mathrm{km} / \mathrm{jam})\end{array}$ & LOS \\
\hline $\begin{array}{l}\text { Pulo } \\
\text { Gebang }\end{array}$ & 3927 & 6900 & 0.59 & 90 & 72 & $\mathrm{C}$ \\
$\begin{array}{l}\text { Kelapa } \\
\text { Gading }\end{array}$ & 3319 & 6900 & 0.50 & 90 & 74 & $\mathrm{C}$ \\
\hline
\end{tabular}

Tabel 7 Perkiraan kinerja ruas jalan tol menggunakan HCM 2000

\begin{tabular}{lcc}
\hline Parameter & $\begin{array}{c}\text { Arah } \\
\text { Pulo Gebang }\end{array}$ & $\begin{array}{c}\text { Arah } \\
\text { Kelapa Gading }\end{array}$ \\
\hline Volume kendaraan (kend/jam/jalur) & 2874 & 2525 \\
Kecepatan arus bebas (km/jam) & 102 & 102 \\
Arus lalu lintas (smp/jam/lajur) & 1275 & 1096 \\
Kecepatan minimum (km/jam) & 102 & 102 \\
Densitas (smp/km/lajur) & 12.5 & 10.7 \\
Maksimum V/C & 0.7 & 0.7 \\
Kapasitas (kend/jam/jalur) & 4106 & 3607 \\
Tingkat pelayanan jalan & $\mathrm{C}$ & $\mathrm{B}$ \\
\hline
\end{tabular}


Tabel 8 Perkiraan arus lalu lintas pasca jalan tol beroperasi

\begin{tabular}{llcccc}
\hline Segmen & \multicolumn{1}{c}{ Arah } & $\begin{array}{c}\text { LHRT } \\
\text { pra operasi } \\
\text { (kend/hari) }\end{array}$ & $\begin{array}{c}\text { LHRT } \\
\text { Jalan tol } \\
\text { (kend/hari) }\end{array}$ & $\begin{array}{c}\text { LHRT } \\
\text { pasca operasi } \\
\text { (kend/hari) }\end{array}$ & $\begin{array}{c}\text { Persentasi } \\
\text { teralihkan } \\
(\%)\end{array}$ \\
\hline 1 & Bekasi & 49921 & 31833 & 18087 & 63.8 \\
& Pulogadung & 70302 & 27966 & 42336 & 39.8 \\
2 & Bekasi & 49668 & 31833 & 17835 & 64.1 \\
3 & Pulogadung & 76314 & 27966 & 48348 & 36.3 \\
& Bekasi & 54542 & 31833 & 22709 & 58.4 \\
& Pulogadung & 61860 & 27966 & 33894 & 45.2 \\
\hline
\end{tabular}

Tabel 9 Perkiraan kinerja ruas jalan pasca jalan tol beroperasi

\begin{tabular}{|c|c|c|c|c|c|c|c|}
\hline $\begin{array}{l}\text { Seg- } \\
\text { men }\end{array}$ & Arah & $\begin{array}{c}\text { Arus } \\
\text { lalu } \\
\text { lintas } \\
\text { (smp/ } \\
\text { jam) }\end{array}$ & $\begin{array}{l}\text { Kapasitas } \\
\text { (smp/jam) }\end{array}$ & $\begin{array}{c}\text { Derajat } \\
\text { kejenuhan }\end{array}$ & $\begin{array}{c}\text { Kecepatan } \\
\text { arus bebas } \\
(\mathrm{km} / \mathrm{jam})\end{array}$ & $\begin{array}{c}\text { Kecepatan } \\
(\mathrm{km} / \mathrm{jam})\end{array}$ & LOS \\
\hline \multirow[t]{2}{*}{1} & Bekasi & 615 & 4950 & 0.13 & 62 & 61 & $\mathrm{C}$ \\
\hline & Pulogadung & 1332 & 4950 & 0.28 & 60 & 60 & $\mathrm{C}$ \\
\hline \multirow[t]{2}{*}{2} & Bekasi & 555 & 4950 & 0.12 & 62 & 61 & $\mathrm{C}$ \\
\hline & Pulogadung & 1432 & 4950 & 0.30 & 60 & 60 & $\mathrm{C}$ \\
\hline
\end{tabular}

Perkiraan kinerja ruas Jalan Bekasi Raya setelah jalan tol beroperasi terlihat pada Tabel 9. Berdasarkan tingkat pelayanan jalan yang dihasilkan yaitu $\mathrm{C}$, maka jalan ini sesuai dengan standar PRI Nomor 34 tahun 2006 memiliki tingkat pelayanan jalan terendah C. Berdasarkan tingkat pelayanan yang dihasilkan, maka pembangunan jalan tol dinilai dapat mengurangi kemacetan pada Jalan Bekasi Raya.

Kinerja jalan kemudian diproyeksikan sampai tahun 2035. Pemilihan tahun 2035 disesuaikan dengan literatur faktor pertumbuhan lalu lintas (i) yang dapat digunakan hanya sampai pada tahun 2035 (KemenPUPR 2017). Data perkiraan kinerja jalan pada tahun 2035 terlihat pada Tabel 10.

Berdasarkan Tabel 10, tingkat pelayanan jalan pada semua segmen menurun menjadi D diakibatkan pertumbuhan lalu lintas yang semakin meningkat. Untuk mencapai tingkat pelayanan jalan minimal $\mathrm{C}$ diperlukan rekomendasi perubahan geometri jalan berdasarkan PRI Nomor 34 tahun 2006, yaitu dengan minimal lebar jalur untuk jalan arteri primer sebesar $11 \mathrm{~m}$.

Tabel 10 Perkiraan kinerja jalan pada tahun 2035

\begin{tabular}{|c|c|c|c|c|c|c|}
\hline \multirow{2}{*}{ Segmen } & \multirow{2}{*}{ Arah } & \multicolumn{2}{|c|}{ LHRT } & \multicolumn{2}{|c|}{ Arus lalu lintas } & \multirow{2}{*}{ LOS } \\
\hline & & (kend/hari) & (smp/hari) & (kend/jam) & $(\mathrm{smp} / \mathrm{jam})$ & \\
\hline \multirow[t]{2}{*}{1} & Bekasi & 39.545 & 14.944 & 3.559 & 1.345 & $\mathrm{D}$ \\
\hline & Pulo gadung & 79.033 & 27.622 & 7.113 & 2.486 & D \\
\hline \multirow[t]{2}{*}{2} & Bekasi & 39.121 & 13.800 & 3.521 & 1.242 & $\mathrm{D}$ \\
\hline & Pulo gadung & 89.102 & 29.444 & 8.019 & 2.650 & $\mathrm{D}$ \\
\hline
\end{tabular}


Rekayasa lalu lintas untuk meningkatkan tingkat pelayanan jalan menjadi C sampai tahun 2035 yaitu dengan menambah lebar lajur lalu lintas yang semula $3.25 \mathrm{~m}$ menjadi $4 \mathrm{~m}$ dengan tipe jalan yang sama yaitu $6 / 2 \mathrm{D}$. Data yang dianalisis berdasarkan volume lalu lintas tahun 2035 atau tahun akhir perencanaan . Hasil rekayasa geometri jalan memiliki kinerja seperti pada Tabel
11. Berdasarkan Tabel 11 maka tingkat pelayanan pada semua segmen menjadi C dan sesuai dengan PRI Nomor 34 tahun 2006. Pelebaran jalur ini, yang semula $9.75 \mathrm{~m}$ menjadi $12 \mathrm{~m}$, dapat mengurangi masalah kemacetan di Jalan Bekasi Raya selain karena volume lalu lintas yang berkurang setelah dibangunnya jalan tol.

Tabel 11 Perkiraan kinerja ruas jalan Bekasi Raya berdasarkan pelebaran lajur

\begin{tabular}{llccccc}
\hline Segmen & Arah & $\begin{array}{c}\text { Kapasitas } \\
(\mathrm{smp} / \mathrm{jam})\end{array}$ & $\begin{array}{c}\text { Arus lalu } \\
\text { lintas } \\
(\mathrm{smp} / \mathrm{jam})\end{array}$ & $\begin{array}{c}\text { Derajat } \\
\text { kejenuhan }\end{array}$ & $\begin{array}{c}\text { Kecepatan } \\
\text { (km/jam) }\end{array}$ & LOS \\
\hline 1 & Bekasi & 5.337 & 1.345 & 0,25 & 66 & $\mathrm{C}$ \\
2 & Pulo gadung & 5.337 & 2.486 & 0,47 & 63 & $\mathrm{C}$ \\
& Bekasi & 5.337 & 1.242 & 0,23 & 67 & $\mathrm{C}$ \\
\hline
\end{tabular}

\section{Perkiraan dampak off ramp Bekasi Raya}

Analisis dampak off ramp Bekasi Raya berdasarkan perhitungan bagian jalinan pada Manual Kapasitas Jalan Indonesia 1997. Metode ini menerangkan pengaruh rata-rata dari kondisi masukan yang diasumsikan. Masukan ini berdasarkan arus lalu lintas yang keluar dari jalan tol dan arus jalan eksisting itu sendiri. Metode ini berlaku untuk derajat kejenuhan lebih kecil dari $0.8-0.9$. Kondisi geometri bagian jalinan yaitu memiliki lebar jalinan $16 \mathrm{~m}$ dan panjang jalinan $300 \mathrm{~m}$. Berdasarkan Tabel 12 perkiraan kinerja jalan sampai tahun 2035 dinilai masih baik dan belum menimbulkan kemacetan yang signifikan, karena nilai derajat kejenuhan kurang dari 0.8. Kondisi geometri jalan yang ada sesuai dengan standar dan tidak memerlukan rekomendasi.

Tabel 12 Perkiraan kinerja jalan bagian jalinan

\begin{tabular}{cccccc}
\hline $\begin{array}{c}\text { Tahun } \\
\text { analisis }\end{array}$ & $\begin{array}{c}\text { Arus lalu } \\
\text { lintas } \\
(\mathrm{smp} / \mathrm{jam})\end{array}$ & $\begin{array}{c}\text { Kapasitas } \\
(\mathrm{smp} / \mathrm{jam})\end{array}$ & $\begin{array}{c}\text { Derajat } \\
\text { kejenuhan }\end{array}$ & $\begin{array}{c}\text { Kecepatan } \\
\text { arus bebas } \\
(\mathrm{km} / \mathrm{jam})\end{array}$ & $\begin{array}{c}\text { Kecepatan } \\
\text { tempuh } \\
(\mathrm{km} / \mathrm{jam})\end{array}$ \\
\hline 2024 & 4996 & 13287 & 0.38 & 35 & 31 \\
2035 & 8367 & 13287 & 0.63 & 34 & 28 \\
\hline
\end{tabular}

\section{KESIMPULAN}

Kondisi jalan eksisting Bekasi Raya saat ini untuk titik 1 pada arah Bekasi memiliki tingkat pelayanan $\mathrm{C}$, sedangkan pada arah Pulogadung memiliki tingkat pelayanan D. Segmen 2 memiliki tingkat pelayanan $\mathrm{E}$ dan segmen 3 memiliki tingkat pelayanan $\mathrm{C}$. Tingkat pelayanan jalan tol berdasarkan metode MKJI 1997 adalah C untuk kedua arah, sedangkan berdasarkan metode HCM 2000, jalan tol memiliki tingkat pelayanan jalan $\mathrm{C}$ untuk arah Pulo Gebang dan B untuk arah Bekasi.

Setelah pembangunan jalan tol, tipe Jalan Bekasi Raya menjadi 6/2D sehingga tingkat pelayanan mengalami peningkatan menjadi C untuk tahun 2024. Tetapi pada tahun 2035 mengalami 
penurunan menjadi D sehingga direkomendasikan untuk penambahan lebar lajur menjadi $4 \mathrm{~m}$ agar dapat meningkatkan tingkat pelayanan jalan menjadi C. Adanya pembangunan jalan tol dinilai dapat mengurangi volume kendaraan di Jalan Bekasi Raya sampai 64.1\% untuk arah Bekasi dan 45.2\% untuk arah Pulogadung (Jakarta). Dampak off ramp untuk jalan tol tidak mengalami kemacetan yang signifikan karena nilai derajat kejenuhan untuk tahun 2024 sampai 2035 masih kurang dari 0.8 .

\section{DAFTAR PUSTAKA}

Alhadar A. 2011. Analisis kinerja jalan dalam upaya mengatasi kemacetan lalu lintas pada ruas simpang bersinyal di Kota Palu. Jurnal Sipil Mesin Arsitektur Elektro (SMARTek). 9(4): 327-336.

Apriliyanto R. 2018. Analisis Kemacetan dan Perkiran Tingkat Pelayanan Jalan pada Masa Mendatang (Studi Kasus Jalan Raya Sawangan Depok) [skripsi]. Bogor (ID): Institut Pertanian Bogor.

[BSN] Badan Standardisasi Nasional. 2008. Standar Geometri Jalan Bebas Hambatan untuk Jalan Tol. RSNI-T-XX-2008. Bandung (ID): BSN.

[DepPU] Departemen Pekerjaan Umum. 1997. Manual Kapasitas Jalan Indonesia (MKJI). Jakarta (ID): Direktorat Jenderal Bina Marga.

[FDT] Florida Department of Transportation. 1995. Florida's Level of Service Standards and Guidelines Manual for Planning. Tallahassee (US): Systems Planning Office.

Jati R P. 2018. Jakarta dan kemacetannya [internet]. [diunduh 2018 Des 20]. Tersedia

dari: http://medium.com/jakarta-dankemacetannya.

Julianto E N. 2010. Hubungan Antara Kecepatan, Volume dan Kepadatan Lalu Lintas Ruas Jalan Siliwangi Semarang. Jurnal Teknik Sipil dan Perencanaan. 2(12): 151-160.

[KemenHub] Kementerian Perhubungan. 2015. Pedoman Pelaksanaan Kegiatan Manajemen dan Rekayasa Lalu Lintas. Peraturan Menteri Perhubungan Republik Indonesia Nomor: PM 96 Tahun 2015. Jakarta (ID): Kementrian Perhubungan.

[KemenPUPR] Kementerian Pekerjaan Umum dan Perumahan Rakyat. 2017. Manual Desain Perkerasan Jalan Revisi 2017. Jakarta (ID): Kementerian Pekerjaan Umum dan Perumahan Rakyat.

Khisty J. C., Lall B. K. 2006. Dasar Dasar Rekayasa Transportasi. Jilid 1 dan Jilid 2. Niro F, penerjemah. Jakarta (ID): Erlangga.

[LBHJakarta] Lembaga Bantuan Hukum Jakarta. 2018. Tolak 6 ruas jalan tol dalam kota: bencana bagi masa depan Jakarta [internet]. [diunduh 2018 Des 20]. Tersedia dari: https://www.bantuanhukum.or.id/t olak-6-ruas-jalan-tol-dalam-kotabencana-bagi-masa-depan-jakarta/

Nathaniel N. 2010. Analisis Kapasitas Jalan Bebas Hambatan Berdasarkan Studi Kasus Rencana Jakarta Outer Ring Road II (JORR II) Ruas Serpong-Cinere dengan Metode US-HCM 2000 [skripsi]. Depok (ID): Universitas Indonesia. Pratomo D S, Astuti KZ. 2015. Analisis Regresi dan Korelasi Antara Pengunjung dan Pembeli Terhadap Nominal Pembelian di Indomaret Kadungwundu Semarang dengan 
Metode Kuadrat Terkecil. Jurnal Statistika. 1(1): 3.

[PRI] Pemerintah Republik Indonesia. 2006. Jalan. Peraturan Pemerintah Republik Indonesia Nomor 34 Tahun 2006. Jakarta (ID) . Sekretariat Negara

Setijadji A. 2006. Studi kemacetan lalu lintas Jalan Kaligawe Kota Semarang [tesis]. Semarang (ID): Universitas Diponegoro.

Susanto B, Santosa W, Budiyono A. 2011. Kepemilikan kendaraan dan pola perjalanan di wilayah Jabodetabek. Jurnal Transportasi. 11(3): 153-162.

[TRB]Transportation Research Board. 2000. Highway Capacity Manual. Washington DC (US): National Research Council.

Widari L A, Akbar S J, Fajar R. 2015. Anaisis tingkat pelayanan jalan (studi kasus Jalan Medan-Banda Aceh km 254 $4^{+800}$ s.d km $256^{+700}$ ). Teras Jurnal. 5(2): 89-98. 